\title{
Electrochemical synthesis of Zinc oxide/polymer/phosphotungstic acid composites for a UV detector
}

\author{
Zulpikar Helii ${ }^{1 a}$, Ruxangul Jamal ${ }^{2 a}$, Mariyam Niyaz ${ }^{1}$, Ahmat Ali $^{3}$, Nurbiye Sawut ${ }^{1}$, Dongna Zou ${ }^{1}$, \\ Huiying Liu', Junxia Li ${ }^{1}$, Tursun Abdiryim ${ }^{1 *}$
}

${ }^{1}$ Key Laboratory of Energy Materials Chemistry, Ministry of Education; Key Laboratory of Advanced Functional Materials, Autonomous Region; Institute of Applied Chemistry, College of Chemistry, Xinjiang University, Urumqi, 830046 P.R. China.

${ }^{2}$ Key Laboratory of Oil and Gas Fine Chemicals, Ministry of Education \& Xinjiang Uygur Autonomous Region, Xinjiang University, Urumqi, 830046 P.R. China.

${ }^{3}$ College of Chemistry and Environmental Engineering, Xinjiang Institute of Engineering, Urumqi 830023, Xinjiang, PR China.

${ }^{a}$ These authors contributed equally to this work.

"Corresponding author: e-mail: tursunabdir@sina.com.cn

\begin{abstract}
$\mathrm{ZnO}$ is an ideal material for $\mathrm{UV}$ detection. However, due to the surface effect of $\mathrm{ZnO}$, the photosensitivity of the $\mathrm{ZnO}$ based UV detector needs to be improved. In this study, we deposited a hydroxyl group functionalized (3,4-propylenethiophene) polymer (PProDOT-OH) film onto a hydrothermally grown $\mathrm{ZnO}$ nanoarray by electrochemical deposition method to prevent the corrosion of $\mathrm{ZnO}$ by phosphotungsten acid (PWA), and then PWA was drip-coated on the composite film to prepare the ZnO/PProDOT-OH/PWA composite based UV detector. The structure and morphology of the composite were characterized by SEM, UV-vis, FT-IR, XRD, Raman, EDS, XPS analysis, illustrating the phosphotungstic acid was uniformly coated on $\mathrm{ZnO} / \mathrm{PProDOT}-\mathrm{OH}$ surface and confirming the composite was successfully synthesized. The UV detection performance was studied through preparing a UV detector with the composite material and results indicate that the introduction of PWA could enhance the responsivity of the $\mathrm{ZnO} / \mathrm{PProDOT}-\mathrm{OH}$ composite-based UV detector.
\end{abstract}

Keywords: UV detector, $\mathrm{ZnO}$, phosphotungsten acid, composite.

\section{INTRODUCTION}

As a new type of direct band gap semiconductor material, $\mathrm{ZnO}$ has a band gap of $3.37 \mathrm{eV}$ and an exciton binding energy as high as $60 \mathrm{meV}^{1,2}$. Compared with $\mathrm{GaN}$ materials, $\mathrm{ZnO}$ has the advantages of lower growth temperature, smaller lattice mismatch, easier doping and lower price ${ }^{3-5}$. Because of these advantages, $\mathrm{ZnO}$ material has gradually become one of the most popular materials for the preparation of UV detectors. Since Mollow et al. discovered that $\mathrm{ZnO}$ materials have photoresponse to UV radiation in the 1940 s, researchers have begun to study on ZnO-based UV detectors ${ }^{6}$. Yang Peidong et al. prepared a $\mathrm{ZnO}$ nanowire-based UV detector with a chemical meteorological deposition $\operatorname{method}^{7}$, the sensitivity of the detector is 4-6 orders of magnitude, and its response time is less than 1s, which showing good UV response characteristics. Bai et al. prepared a $\mathrm{ZnO}$ nanowire based UV detector on a PET flexible film $^{8}$, the device has an on-off ratio of about 120,000, a photocurrent of $14.1 \mathrm{~mA}$ and a dark current of 110 nA, which exhibiting excellent performance, however, the photocurrent response time of this device exceeds $500 \mathrm{~s}$, and the recovery time is as high as $570 \mathrm{~s}$, and this kind of performance is suitable for some fields where the current requirement is high but the response time of the device is low. Therefore, it is necessary to develop an UV detector that can balance the both response time and responsivity.

Since the first heteropoly phosphomolybdic acid was successfully synthesized by J. Berzerius in 1826, polyoxometalate has a history of more than 150 years and has become an important research field of inorganic chemistry $^{9-12}$. Many studies have confirmed that heteropoly acids have similar electronic structure characteristics to semiconductors ${ }^{13,14}$. When light is irradiated, heteropoly acid molecules will attain energy, and the electrons in the molecule can transit from the highest full electron molecular orbital HOMO to the lowest empty molecular orbital LUMO to produce an empty orbital ${ }^{15-18}$. This property makes heteropolyacids receive extensive attention in the field of photoelectrochemistry ${ }^{\mathbf{1 9}} \mathbf{2 0}$. Sun et al. prepared a detector device made of phosphotungstic acid and $\mathrm{TiO}_{2}$ composite material by a knife coating method ${ }^{21}$. Compared with the pure $\mathrm{TiO}_{2}$ detector device, the photocurrent of the phosphotungstic acid/ $\mathrm{TiO}_{2}$ composite material detector device was increased by about 2000 times. It can be inferred that heteropoly acids can be introduced into semiconductor-based UV detectors to prepare better heteropoly acid/semiconductor composite UV detectors. The composites with better properties can be obtained by modifying $\mathrm{ZnO}$ with heteropoly acid, but heteropoly acid may cause the corrosion of $\mathrm{ZnO}$, so we consider coating $\mathrm{ZnO}$ with polymer (PProDOT-OH) film first and then introducing heteropoly acid to avoid the corrosion of $\mathrm{ZnO}$.

In this study, we deposited a hydroxy-functionalized (3,4-propylenethiophene) polymer (PProDOT-OH) film onto a hydrothermally grown $\mathrm{ZnO}$ nanoarray by electrochemical deposition method, and then phosphotungsten acid (PWA) was drip-coated on the composite film to prepare the $\mathrm{ZnO} / \mathrm{PProDOT}-\mathrm{OH} / \mathrm{PWA}$ based UV detector. Because the high electronic transition ability of $\mathrm{ZnO} / \mathrm{PProDOT}-\mathrm{OH}$ at low energy, and recombination of photogenerated electrons with $\mathrm{ZnO}$ can be inhibited by the coupling effect between $\mathrm{ZnO}$ and polymer, Moreover heteropoly acid is a good type of electron acceptor and can also be used as a trap for electrons. It can act as a bridge for electron transmission, capture the photogenerated electrons generated by the conduction band (VB) of semiconductor materials, and then transfer them 
to improve the photoelectric performance of materials. we hypothesize that the introduction of phosphotungstic acid into $\mathrm{ZnO}$ can obtain a UV detector with better photoelectric properties than pure $\mathrm{ZnO}$ nanoarrays.

\section{EXPERIMENTAL}

Preparation of the $\mathrm{ZnO/PProDOT-OH/PWA} \mathrm{composite}$

The monomer of PProDOT-OH was synthesized based on a literature report ${ }^{22}$. $\mathrm{ZnO}$ nanoarrays were prepared according to the hydrothermal method used in the literature ${ }^{23}$. Firstly, the seed layer of $\mathrm{ZnO}$ nanoarray was prepared by sol-gel method. An aqueous solution for the growth of $\mathrm{ZnO}$ was prepared using hexamethylenetetramine $(25 \mathrm{mM})$ and zinc nitrate $(25$ $\mathrm{mM}$ ). Then, place a piece of FTO coated with a $\mathrm{ZnO}$ seed layer in an autoclave oven at $95{ }^{\circ} \mathrm{C}$ for 4 hours. Secondly, to fabricate the $\mathrm{ZnO} / \mathrm{PProDOT}-\mathrm{OH}$ composite, ProDOT-OH monomers were electropolymerized on hydrothermally grown $\mathrm{ZnO}$ nanoarrays by cyclic voltammetry in $0.01 \mathrm{M}$ ProDOT-OH monomer and 0.05 $\mathrm{M}$ tetrabutylammonium hexafluorophosphate $\left(\mathrm{TBAPF}_{6}\right)$ dichloromethane as solvents, and a thin PProDOT-OH polymer film was formed on $\mathrm{ZnO}$ nanoarrays, indicating that the monomers were successfully polymerized onto $\mathrm{ZnO}$ nanoarrays. Finally, $\mathrm{ZnO} / \mathrm{PProDOT}-\mathrm{OH} /$ PWA is prepared by dripping phosphotungstic acid ethanol solution onto $\mathrm{ZnO} / \mathrm{PProDOT}-\mathrm{OH}$ composite. The phosphotungstic acid (PWA) ethanol solution with a concentration of $30 \mathrm{mM}$ was slowly dripped onto the $\mathrm{ZnO} / \mathrm{PProDOT}-\mathrm{OH}$ composite and then dried naturally to obtain $\mathrm{ZnO} / \mathrm{PProDOT}-\mathrm{OH} / \mathrm{PWA}$ ternary composites.

\section{Fabrication of the UV detectors}

Two pieces of FTO conductive glass which respectively grown with $\mathrm{ZnO}$ nanoarrays and $\mathrm{ZnO} / \mathrm{PProDOT}-\mathrm{OH} /$ PWA were affixed back-to-back and clamped with a clip to fabricate the device. Notably, the silver pulp was used as the contact point. Use an electrochemical instrument (CHI660) to measure the photoresponse (I-T) and I-V characteristics of the device under UV irradiation with a wavelength of $\lambda=365 \mathrm{~nm}$, and the light intensity was $0.4 \mathrm{~mW} / \mathrm{cm}^{2}$ provided by a ZF-20A dark box four UV analyzer that purchased from Shanghai Yuezhong Instrument and Equipment Co., Ltd.

\section{RESULTS AND DISCUSSION}

\section{SCANNING ELECTRON MICROSCOPE (SEM)}

Figure 1 shows the scanning electron microscope of $\mathrm{ZnO}, \mathrm{ZnO} / \mathrm{PProDOT}-\mathrm{OH}$ and $\mathrm{ZnO} / \mathrm{PProDOT}-\mathrm{OH} / \mathrm{PWA}$. Figure 1(a) and (d) show the top-view and cross-sectional SEM images of the uniformly formation of pure $\mathrm{ZnO}$ nanoarray, respectively. From Figures 1(b) and (e), it can be seen that PProDOT-OH grows on the $\mathrm{ZnO}$ nanoarrays in a fibrous form, and is densely distributed on the $\mathrm{ZnO}$ nanoarrays. Figure $1(\mathrm{c})$ is the top-view scanning electron microscope of $\mathrm{ZnO} / \mathrm{PProDOT}-\mathrm{OH} /$ PWA composites. It can be found that phosphotungstic acid is uniformly coated on $\mathrm{ZnO} / \mathrm{PProDOT}-\mathrm{OH}$, and its morphology is obviously different from that of $\mathrm{ZnO} /$ PProDOT-OH, indicating that $\mathrm{ZnO} / \mathrm{PProDOT}-\mathrm{OH} / \mathrm{PWA}$ was successfully prepared. The difference between the $\mathrm{ZnO} / \mathrm{PProDOT}-\mathrm{OH} / \mathrm{PWA}$ and $\mathrm{ZnO} / \mathrm{PProDOT}-\mathrm{OH}$ can also be found from the cross-sectional view of the $\mathrm{ZnO}$ / PProDOT-OH/PWA in Figure 1(f).

\section{UV-vis spectra}

The UV-vis spectra of $\mathrm{ZnO}$, PWA and $\mathrm{ZnO} / \mathrm{PPro}-$ DOT-OH/PWA composites are shown in Figure 2(a). It can be seen that $\mathrm{ZnO}$ and $\mathrm{ZnO} / \mathrm{PProDOT}-\mathrm{OH} / \mathrm{PWA}$ both exhibit a $\mathrm{ZnO}$ band edge absorption at $365 \mathrm{~nm}$, and the PWA and $\mathrm{ZnO}$ have strong absorption peaks in the UV light region. The absorption peaks of about 287-365 nm in ZnO/PProDOT-OH/PWA composites are formed by the overlapping of UV absorption peaks of PWA and $\mathrm{ZnO}$, which is consistent with the previous literature report ${ }^{21}$.
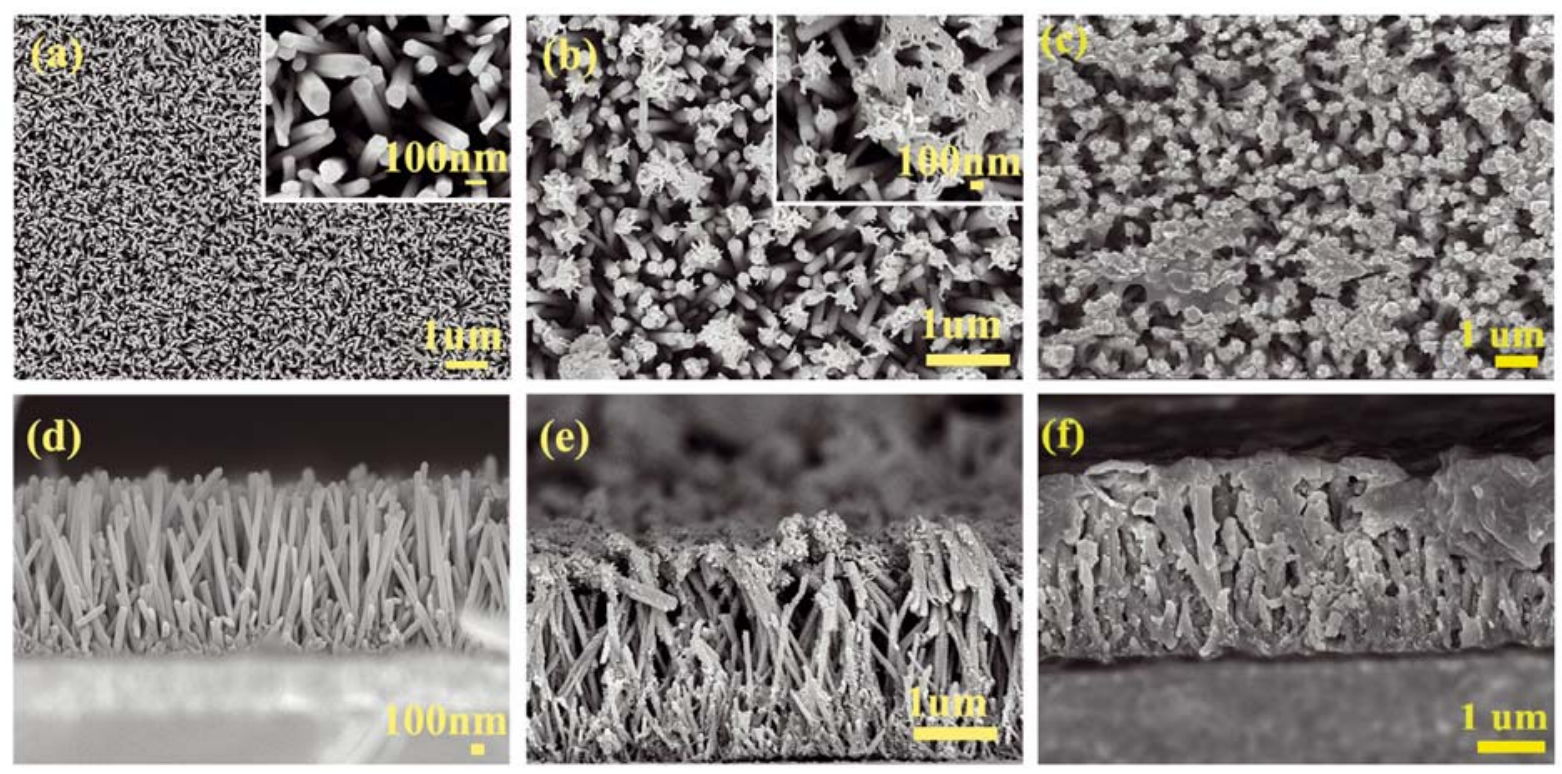

Figure 1. Top-view SEM images of (a) $\mathrm{ZnO}$ (b) ZnO/PProDOT-OH, (c) ZnO/ PProDOT-OH/PWA, cross-sectional SEM images of (d) $\mathrm{ZnO}$, (e) $\mathrm{ZnO} / \mathrm{PProDOT}-\mathrm{OH}$, (f) $\mathrm{ZnO} / \mathrm{PProDOT}-\mathrm{OH} / \mathrm{PWA}$ 

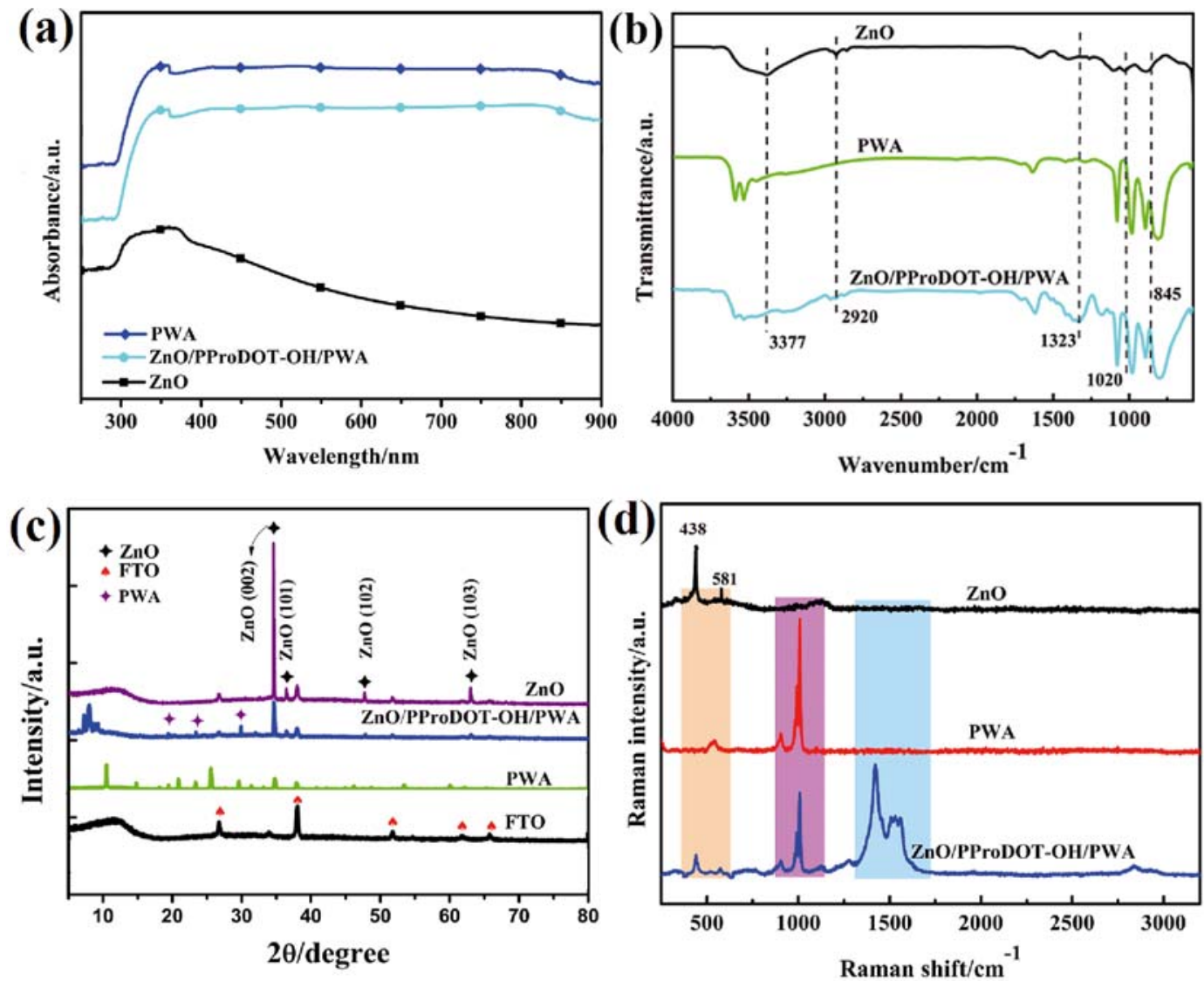

Figure 2. (a) UV-vis, (b) FTIR, (c) XRD, (d) Raman spectra of ZnO, PWA, ZnO/PProDOT-OH/PWA composite

\section{FT-IR spectra}

Figure 2(b) presents the FT-IR spectra of $\mathrm{ZnO}$, PWA and $\mathrm{ZnO} / \mathrm{PProDOT}-\mathrm{OH} / \mathrm{PWA}$ composites. As shown in Figure 2(b), the absorption peaks near 3377, 2920, 1695, $1408,870 \mathrm{~cm}^{-1}$ belong to hydroxyl groups adsorbed on the surface of $\mathrm{ZnO}^{24}$. In which, the absorption peaks at $1614 \mathrm{~cm}^{-1}$ and $1323 \mathrm{~cm}^{-1}$ attribute to the stretching vibration of $\mathrm{C}=\mathrm{C}$ and $\mathrm{C}-\mathrm{C}$ in the thiophene ring, while the absorption peaks at 1139,1080 and $1020 \mathrm{~cm}^{-1}$ are associated with the stretching vibration of $\mathrm{C}-\mathrm{O}-\mathrm{C}$ and C-S-C, respectively ${ }^{25}$. ZnO/PProDOT-OH/PWA have strong characteristic absorption peaks at 1614, 1323, 1139, $1080,1020,845,700 \mathrm{~cm}^{-1}$. In a word, the characteristic peaks of PProDOT-OH are appeared in the spectra of $\mathrm{ZnO} / \mathrm{PProDOT}-\mathrm{OH} / \mathrm{PWA}$, indicating that PProDOT-OH were successfully deposited on $\mathrm{ZnO}$ nanoarrays. In PWA and $\mathrm{ZnO} / \mathrm{PPrODOT}-\mathrm{OH} / \mathrm{PWA}$, the characteristic peaks at $3589,1654,1070,882,904,811 \mathrm{~cm}^{-1}$ belong to P-Oa, $\mathrm{W}=\mathrm{Od}, \mathrm{W}-\mathrm{Ob}-\mathrm{W}$ and $\mathrm{W}-\mathrm{Oc}-\mathrm{W}$ stretching vibrations in PWA, respectively ${ }^{26}$. The characteristic peaks of PWA can be observed in both pure PWA and $\mathrm{ZnO} /$ PProDOT-OH/PWA composites, which indicated that the PWA has been successfully recombined into $\mathrm{ZnO} / \mathrm{PProDOT}-\mathrm{OH}$.

\section{XRD analysis}

Figure 2(c) shows the XRD pattern of $\mathrm{ZnO}$ and $\mathrm{ZnO} /$ PProDOT-OH/PWA composite. As is shown in Figure 2(c), the XRD spectra of $\mathrm{ZnO}$ and $\mathrm{ZnO} / \mathrm{PProDOT}-\mathrm{OH} /$ PWA composites show several characteristic peaks of $\mathrm{ZnO}$. The diffraction peaks at $2 \theta=34.61^{\circ}, 36.82^{\circ}, 47.8^{\circ}$ and $62.9^{\circ}$ correspond to $\mathrm{ZnO}$ (002), $\mathrm{ZnO}$ (101), $\mathrm{ZnO}$ (102) and $\mathrm{ZnO}$ (103), respectively ${ }^{27}$. The peak of (002) is stronger than (101), (102) and (103), indicating that the $\mathrm{ZnO}$ nanoarrays prepared in this work tended to grow along the c-axis. However, the diffraction characteristic peak of $\mathrm{ZnO}(002)$ in $\mathrm{ZnO} / \mathrm{PProDOT}-\mathrm{OH} / \mathrm{PWA}$ composites is weaker than that in pure $\mathrm{ZnO}$, which may be because $\mathrm{ZnO}$ is covered by PProDOT-OH polymer. The characteristic diffraction peaks of $\mathrm{ZnO}$ and PWA can be found in $\mathrm{ZnO} / \mathrm{PProDOT}-\mathrm{OH} / \mathrm{PWA}$ at the same time, indicating that $\mathrm{ZnO} / \mathrm{PProDOT}-\mathrm{OH} / \mathrm{PWA}$ have been successfully prepared. The diffraction peaks at $2 \theta=26.8^{\circ}, 38.01^{\circ}, 51.8^{\circ}, 62.06^{\circ}, 66^{\circ}$ are the diffraction peaks of FTO conductive glass base.

\section{Raman spectra}

The Raman spectra of $\mathrm{ZnO}$, PWA and $\mathrm{ZnO}$ /PProDOT$-\mathrm{OH} / \mathrm{PWA}$ is displayed in Figure 2(d). As shown in the Figure, two peaks can be seen in the Raman spectra of $\mathrm{ZnO}$ nanoarrays and composites at $439 \mathrm{~cm}^{-1}$ and $584 \mathrm{~cm}^{-1}$, which are originated from the $\mathrm{E}_{2}$ and $\mathrm{A}_{1}(\mathrm{LO})$ modes of $\mathrm{ZnO}$. However, the A1 (TO) and E1 (TO) did not appear in the Raman spectra, which indicates that the $\mathrm{ZnO}$ nanoarrays are highly oriented along the $\mathrm{C}$ axis ${ }^{28}$. In Raman spectra, PWA has absorption peaks around 544,914 and $1010.9 \mathrm{~cm}^{-1}$, and these three absorption peaks can also be observed in $\mathrm{ZnO} / \mathrm{PProDOT}-\mathrm{OH} / \mathrm{PWA}$, indicating that PWA has been successfully integrated into $\mathrm{ZnO} / \mathrm{PProDOT}-\mathrm{OH}$ films.

\section{Elemental mapping and Energy-dispersive spectroscopy}

The scanning electron microscope mapping images of $\mathrm{ZnO} /$ PProDOT-OH/PWA are shown in Figure 3. It can be seen that there are seven elements of $\mathrm{C}, \mathrm{O}, \mathrm{S}, \mathrm{F}, \mathrm{Zn}$, $\mathrm{W}$, and $\mathrm{P}$ in composites. The $\mathrm{C}, \mathrm{O}$ and $\mathrm{S}$ in the mapping diagram are derived from the polymer PProDOT-OH, while the $\mathrm{O}$ and $\mathrm{Zn}$ are from the semiconductor $\mathrm{ZnO}$. 

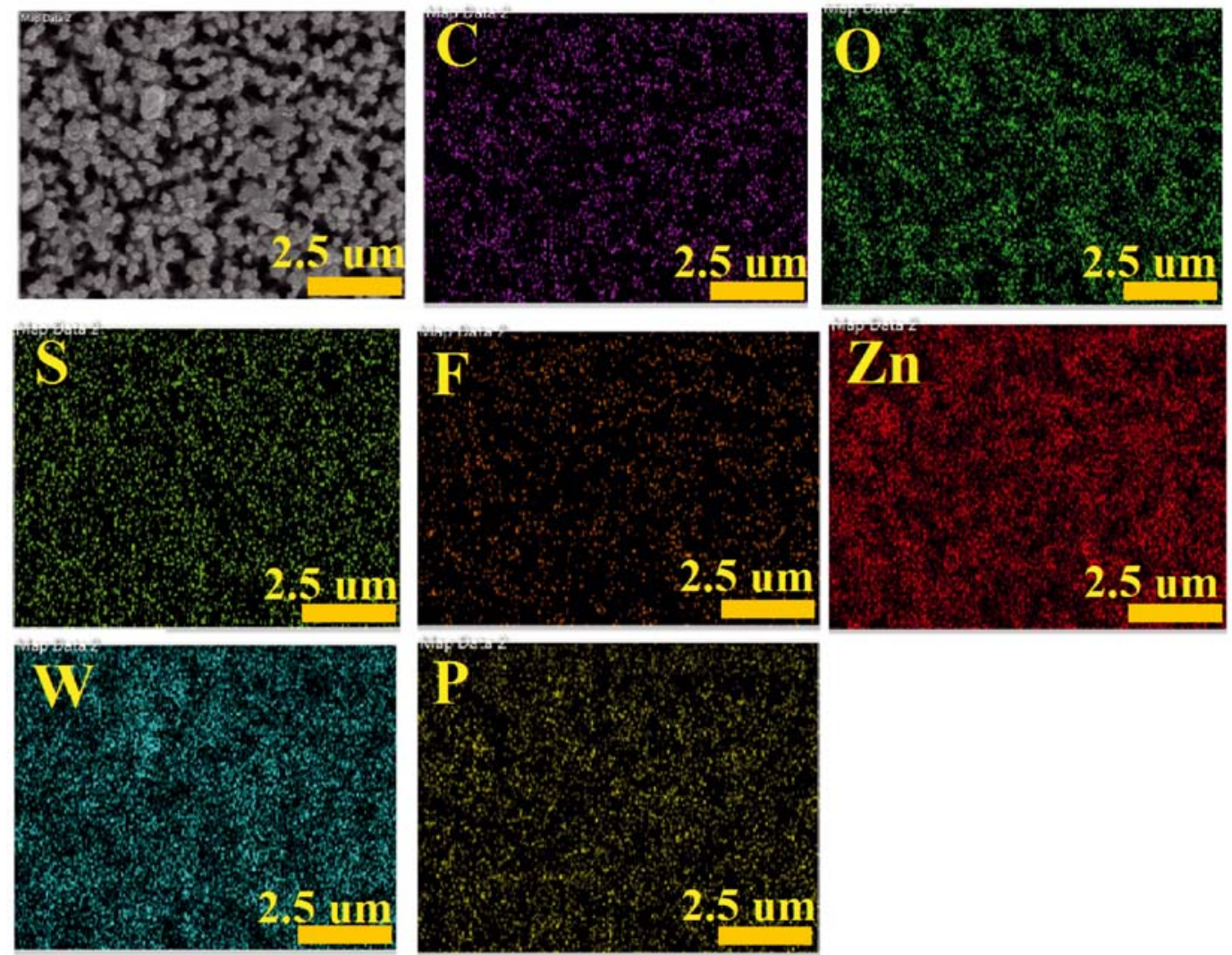

Figure 3. Mapping images of $\mathrm{ZnO} / \mathrm{PProDOT}-\mathrm{OH} / \mathrm{PWA}$ composite

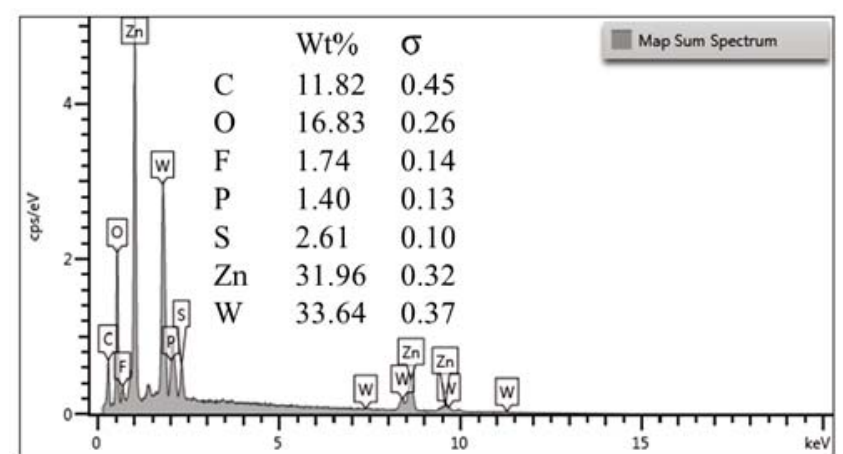

Figure 4. EDS images of $\mathrm{ZnO} / \mathrm{PProDOT}-\mathrm{OH} / \mathrm{PWA}$ composite

The uniform distribution of $\mathrm{F}$ and $\mathrm{P}$ elements can also be observed in the diagram, and these elements were originated from the $\mathrm{TBAPF}_{6}$ which was used as the electrolyte for the polymer deposition. In addition, the relatively uniform of $\mathrm{W}$ in the composites confirmed that PWA has been successfully compounded into $\mathrm{ZnO} /$ PProDOT-OH. Figure 4 shows the EDS images of $\mathrm{ZnO} /$ PProDOT-OH/PWA composites. It is also clear from EDS that $\mathrm{ZnO} /$ PProDOT-OH/PWA have been successfully prepared.

\section{X-ray photoelectron spectroscopy}

Figure 5 presents the XPS spectra of $\mathrm{ZnO} /$ PProDOT-OH/PWA composite. The full spectrum of the composite shows the signal peaks corresponding to $\mathrm{C} 1 \mathrm{~s}$ (281.78 eV), O1s (528.88 eV), S2p (162.88 eV), Zn2p1/2 (1044.88 eV), Zn2p3/2 (1019.78 eV), W4f7/2 (34.88eV) and W4f $5 / 2(38.78 \mathrm{eV})$, respectively, and indicating that the existence of $\mathrm{C}, \mathrm{O}, \mathrm{S}, \mathrm{Zn}, \mathrm{W}$ and $\mathrm{P}$ elements on the $\mathrm{ZnO} / \mathrm{PProDOT}-\mathrm{OH} / \mathrm{PWA}$ composite. The S $2 \mathrm{p}$ spectra show the double peaks of the orbital spin splitting at $164.41(\mathrm{~S} 2 \mathrm{p} 3 / 2)$ and $163.01 \mathrm{eV}(\mathrm{S} \mathrm{p} 1 / 2)$ that originated from PProDOT-OH. O 1s displays the peaks at 530.12 and $532.56 \mathrm{eV}$ for $\mathrm{C}-\mathrm{O}$ and $\mathrm{C}-\mathrm{O}-\mathrm{C}$. The binding energies of $\mathrm{W} 4 \mathrm{f} 7 / 2$ and $\mathrm{W} 4 \mathrm{f} 5 / 2$ are $34.88 \mathrm{eV}$ and $38.78 \mathrm{eV}$, respectively, that derived from the $\mathrm{W}$ atom in PWA. The binding energy peak at $139.58 \mathrm{eV}$ comes from P2p in PWA. The XPS results once again proved that PWA was successfully compounded into $\mathrm{ZnO} / \mathrm{PProDOT}-\mathrm{OH}$, which was consistent with the test results of UV-Vis, FTIR and Mapping and EDS.

\section{Photoelectric performance of the composite}

Figure 6 shows the $\mathrm{I}-\mathrm{V}$ curves of $\mathrm{ZnO}$ and $\mathrm{ZnO} /$ PProDOT-OH/PWA composite-based UV detector. Both $\mathrm{ZnO}$ and $\mathrm{ZnO} /$ PProDOT-OH/PWA composite-based UV detectors have good rectifying characteristics, which show that the introduction of PWA does not affect the structure of the ZnO-based UV detector, and the photocurrent of the device increases obviously. As can be seen in Figure 6(a) and (b), the photocurrent of the detector increased from the original $0.9 \mathrm{~mA}$ to $9.1 \mathrm{~mA}$ after the introduction of PWA, which leads to the improvement of the photoresponsivity (R), external quantum efficiency $(\mathrm{EQE} \%)$ and the detection rate $(\mathrm{D})$ of the $\mathrm{ZnO} /$ PProDOT-OH/PWA based UV detector. Related to pure ZnO-based UV detectors, the optical responsivity (R) of $\mathrm{ZnO} / \mathrm{PProDOT}-\mathrm{OH} / \mathrm{PWA}$ composite increased from the original $2.5 \mathrm{~A} \mathrm{~W}^{-1}$ to $42 \mathrm{~A} \mathrm{~W}^{-1}$, the external quantum efficiency (EQE\%) increased from $850 \%$ to $14240 \%$, and the detectivity (D) increased from the original $2.21 * 10^{11}$ Jones to $2.8 * 10^{12}$ Jones. The photoresponsivity(R) can be calculated by the following formula:

$\mathrm{R}=\left(\mathrm{I}_{\mathrm{ph}}-\mathrm{I}_{\mathrm{dark}}\right) /(\mathrm{P} * \mathrm{~S})$

Where $\mathrm{I}_{\mathrm{ph}}$ represents the photocurrent of the UV detector, $\mathrm{I}_{\text {dark }}$ denotes the dark current of the UV detector, $\mathrm{P}$ is the UV light intensity, and S is the light-receiving area. 

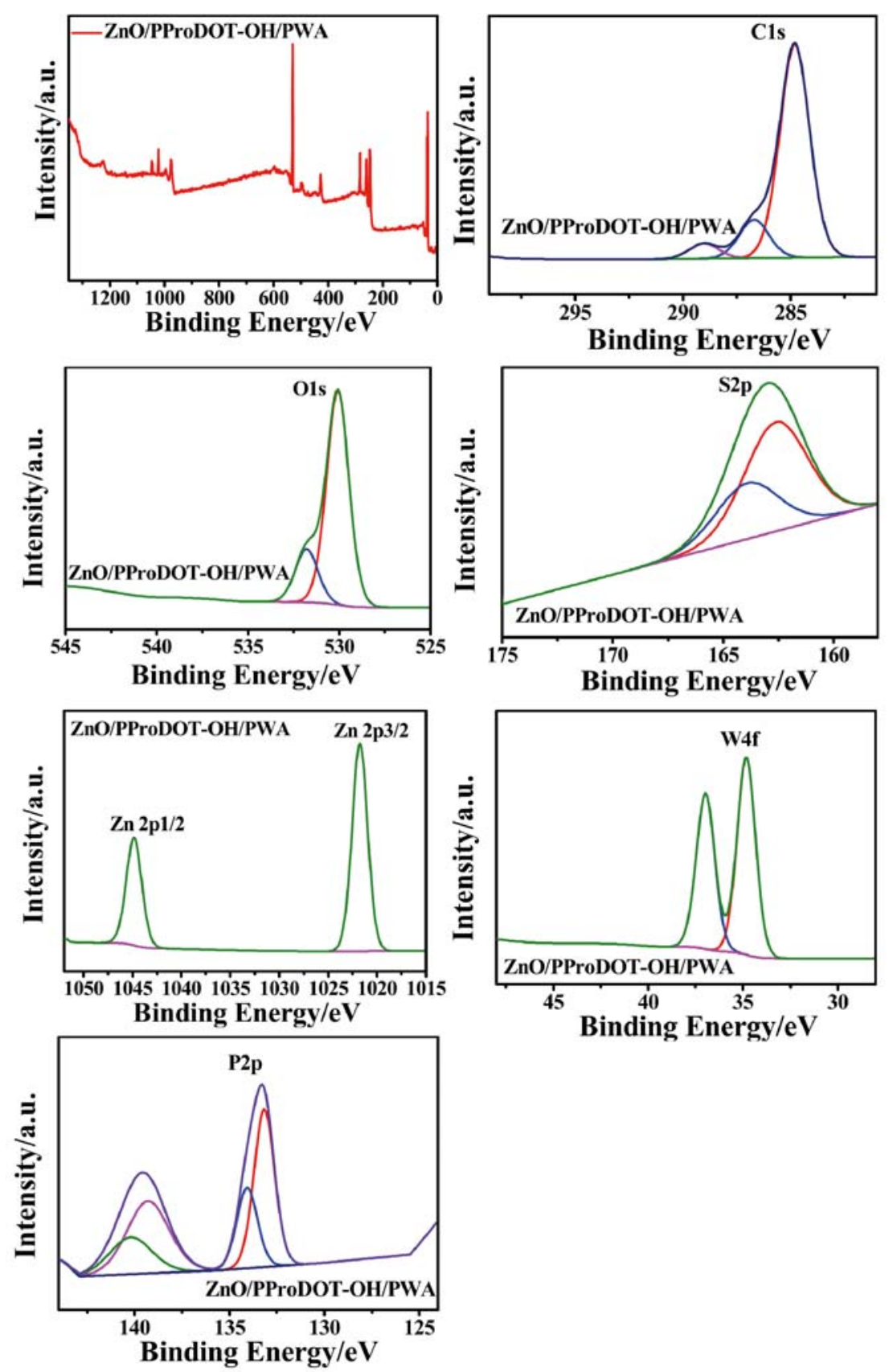

Figure 5. XPS spectra of $\mathrm{ZnO} / \mathrm{PProDOT}-\mathrm{OH} / \mathrm{PWA}$ composite

The comparison between the UV detection properties of the composite prepared in this work and the previously reported materials is shown in Table 1.

Figure 7 shows the Tafel curves of the $\mathrm{ZnO}$ and $\mathrm{ZnO} / \mathrm{PProDOT}-\mathrm{OH} / \mathrm{PWA}$. As shown in Figure 7, the photocurrent of the $\mathrm{ZnO}$ nanoarrays $\mathrm{UV}$ detector that measured under $365 \mathrm{~nm}$ UV radiation is significantly improved than without UV illumination. Compared with the $\mathrm{ZnO} \mathrm{UV}$ detector, the photocurrent of the composite-based UV detector is enhanced after the introduction of PWA, which is caused by the synergism between PWA and $\mathrm{ZnO}$.

Figure 8 shows the I-T curves of the $\mathrm{ZnO}$ and $\mathrm{ZnO} /$ PProDOT-OH/PWA as illuminated by UV radiation at $365 \mathrm{~nm}$. It can be seen from the figure that the rise time $\left(\mathrm{T}_{\text {rise }}\right)$ and fall time $\left(\mathrm{T}_{\text {fall }}\right)$ of the pure $\mathrm{ZnO}$ based UV detector were $395 \mathrm{~s}$ and $752 \mathrm{~s}$, the photocurrent is $0.91 \mathrm{~mA}$, and after the introduction of PWA the $\mathrm{T}_{\text {rise }}$ and $\mathrm{T}_{\text {fall }}$ were decreased to $154 \mathrm{~s}$ and $333 \mathrm{~s}$, respectively.

When the UV light irradiates on the surface of $\mathrm{ZnO}$ semiconductors, $\mathrm{ZnO}$ can absorb photons and immediately produce the photogenerated electron-hole pairs, which rapidly increases the electron density in the $\mathrm{ZnO}$, resulting in the instantaneous increase of photogenerated current. The slow rise is mainly caused by the defects and oxygen vacancies on the surface of $\mathrm{ZnO}$, which is related to the adsorption and desorption of oxygen molecules on the surface of $\mathrm{ZnO}$. The longer light response time of the pure $\mathrm{ZnO} \mathrm{UV}$ detector is mainly due to the slow transmission speed of photogenerated carriers that caused by the defects and oxygen vacancies on the of $\mathrm{ZnO}$. As a kind of semiconductor material, PWA has a molecular orbital structure that similar to the $\mathrm{WO}_{3}$ and $\mathrm{TiO}_{2}$ semiconductor oxides, and it is a kind of excellent electron acceptor. After introducing the PWA into $\mathrm{ZnO}$, it can adsorb the photogenerated electrons inside $\mathrm{ZnO}$ to its molecules, to achieve the purpose of inhibiting photogenerated carrier recombination, and 

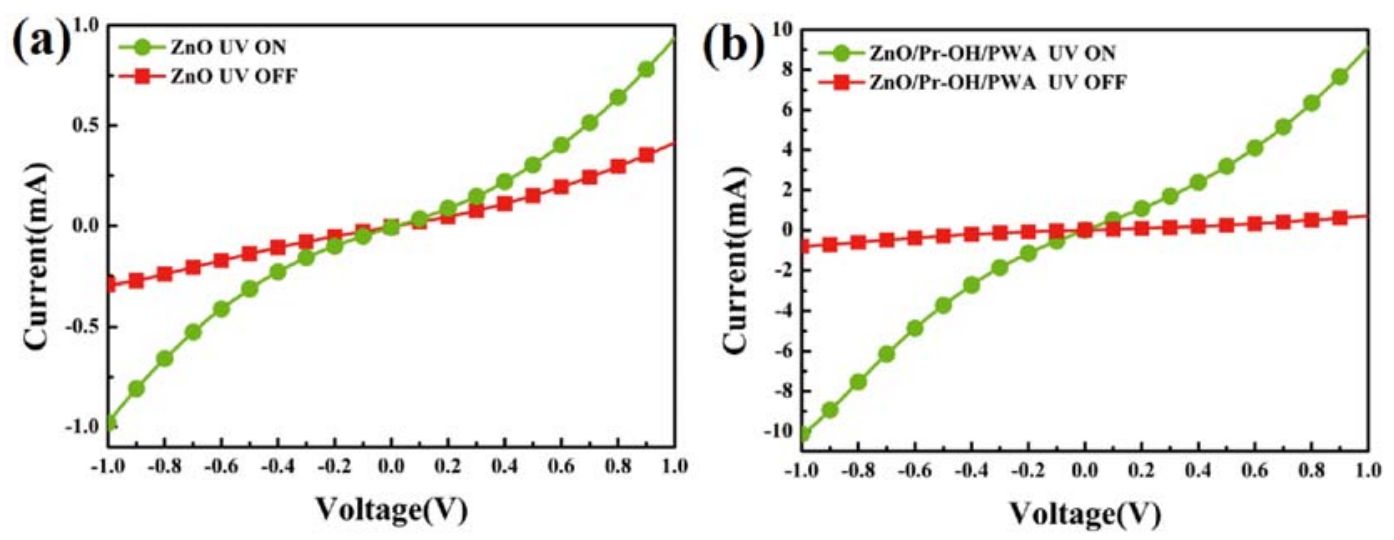

Figure 6. $\mathrm{I}-\mathrm{V}$ behaviors of $\mathrm{ZnO}$ and $\mathrm{ZnO} / \mathrm{PProDOT}-\mathrm{OH} / \mathrm{PWA}$ composite
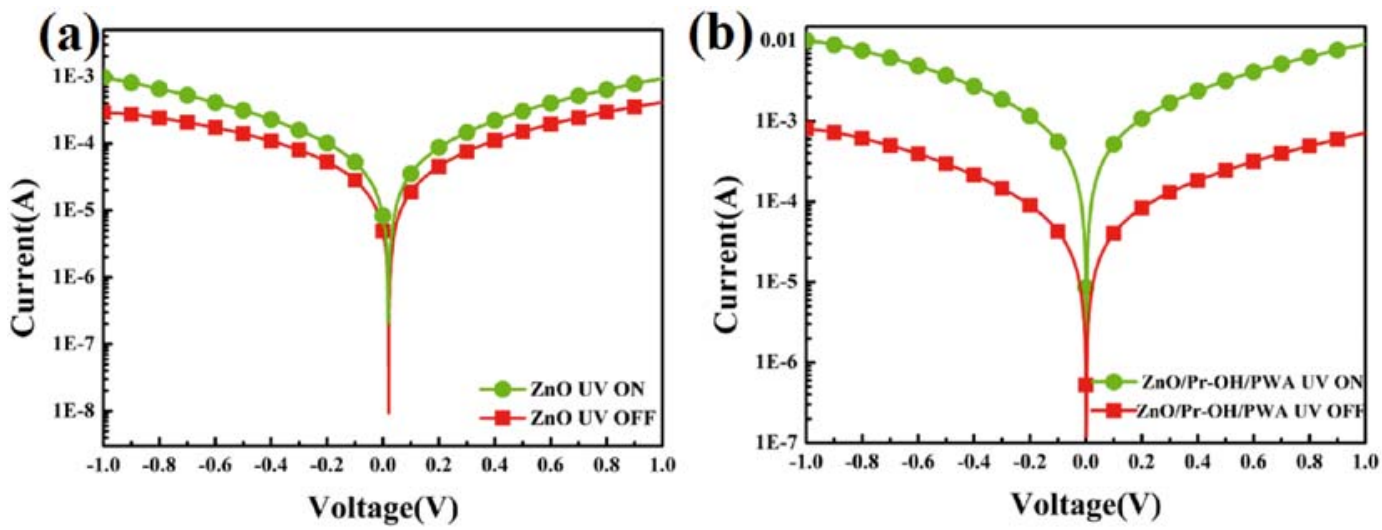

Figure 7. $\mathrm{I}-\mathrm{V}$ curves of $\mathrm{ZnO}$ and $\mathrm{ZnO} / \mathrm{PProDOT}-\mathrm{OH} / \mathrm{PWA}$ composite

Table 1. Characteristics of bed of particles ${ }^{32}$

\begin{tabular}{|c|c|c|c|c|c|}
\hline Materials & $\lambda(\mathrm{nm})$ & $\mathrm{R}\left(\mathrm{A} \cdot \mathrm{W}^{-1}\right)$ & $\mathrm{D}^{*}(\mathrm{Jones})$ & $\mathrm{EQE}(\%)$ & $\mathrm{Ref.}$ \\
\hline In-doped ZnO NRs & 390 & 2.5 & $1.44 \times 10^{11}$ & - & 29 \\
\hline Ga doped ZnO & 374 & 1.68 & - & 55.7 & 30 \\
\hline ZnO thin-films & 365 & 24.38 & $4.6 \times 10^{12}$ & 8283 & 31 \\
\hline ZnO/NPB & 360 & 0.037 & $3.66 \times 10^{9}$ & 12.86 & 32 \\
\hline ZnO NWs & 360 & 0.39 & $1.9 \times 10^{8}$ & $>100$ & 33 \\
\hline ZnO & 365 & 2.5 & $2.2 \times 10^{11}$ & 850 & This work \\
\hline ZnO/PProDOT-OH/PWA & 365 & 42 & $2.8 \times 10^{12}$ & 14240 & This work \\
\hline
\end{tabular}
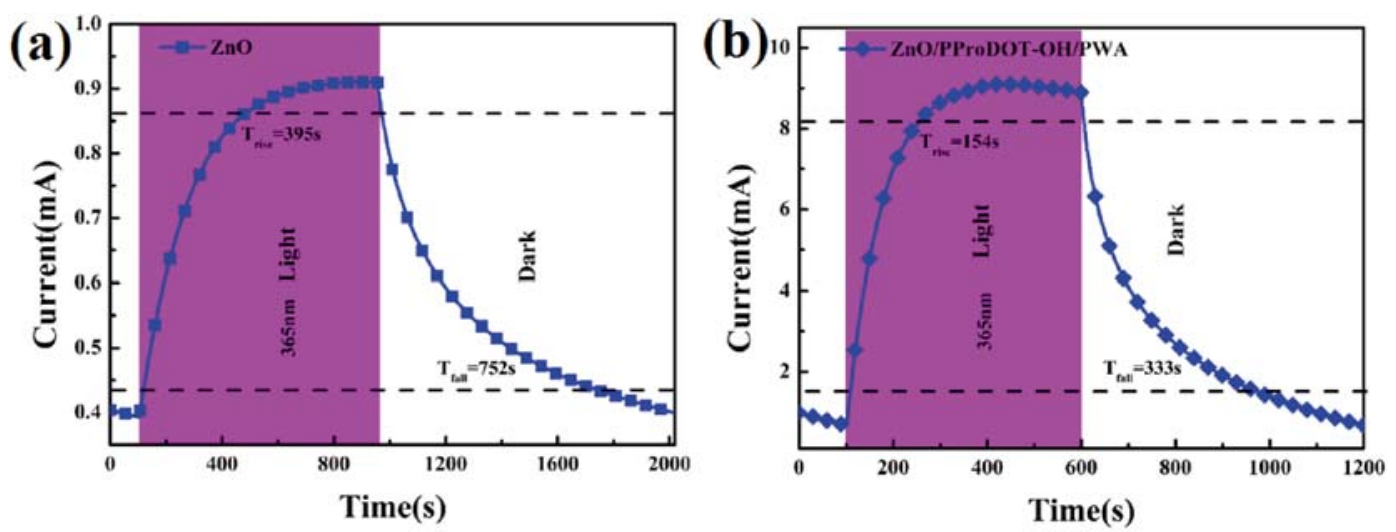

Figure 8. Time response curves of $\mathrm{ZnO}$ and $\mathrm{ZnO} / \mathrm{PProDOT}-\mathrm{OH} / \mathrm{PWA}$ composite

further enhance the photoelectric conversion ability of the composite material.

Figure 9 presents the time-dependent photocurrent response of UV detectors prepared by $\mathrm{ZnO}$ and $\mathrm{ZnO} /$ PProDOT-OH/PWA composite. As shown in Figure 9, the ZnO/PProDOT-OH/PWA composite-based UV detector shows good UV detection performance. Under $365 \mathrm{~nm}$ UV illumination, the photocurrent reaches the maximum values within a certain period of time and maintains this state, which indicates that the composite-based UV de- tector exhibited good stability. Compared with the pure $\mathrm{ZnO}$-based UV detector, after the introduction of PWA, the $\mathrm{ZnO} / \mathrm{PProDOT}-\mathrm{OH} / \mathrm{PWA}$ composite-based UV detectors show fast, stable and repeatable photoconductive switching behavior. The excellent photoelectric response properties of $\mathrm{ZnO} / \mathrm{PProDOT}-\mathrm{OH} / \mathrm{PWA}$ composite can be attributed to the fact that oxygen adsorption and desorption play an important role in the photoconductive gain of $\mathrm{ZnO}$ nanorods in the photoelectric response process. However, the process of oxygen adsorption and 

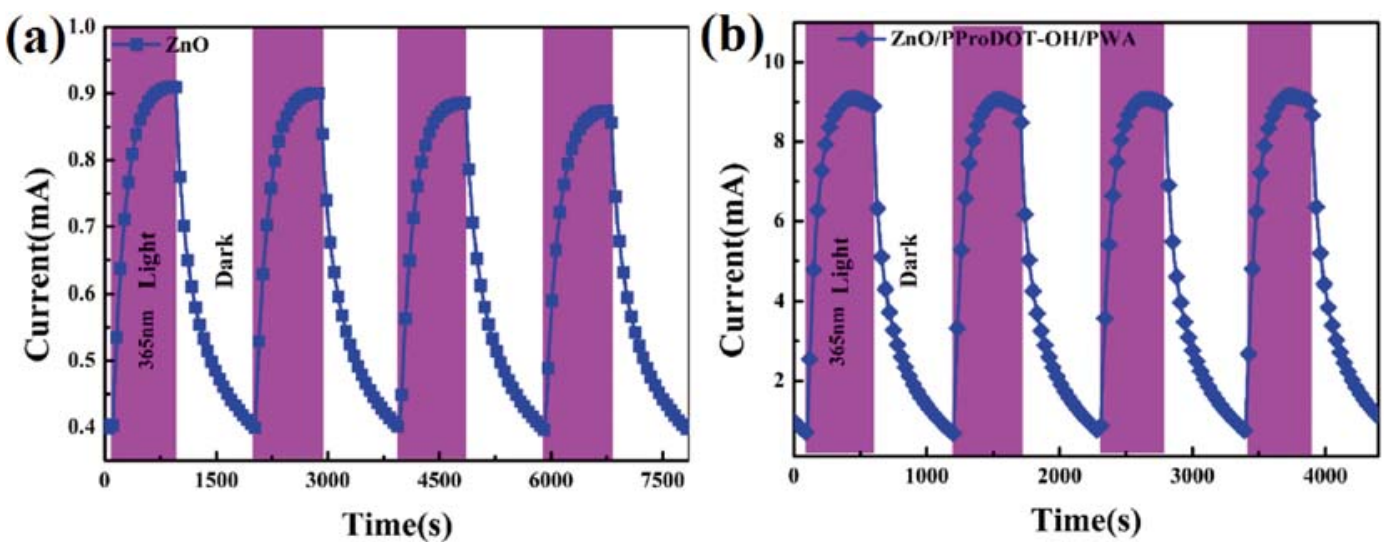

Figure 9. Time-dependent photocurrent response of $\mathrm{ZnO}$ and $\mathrm{ZnO} / \mathrm{PProDOT}-\mathrm{OH} / \mathrm{PWA}$ composite

desorption on the surface of $\mathrm{ZnO}$ is relatively slow, and there are oxygen vacancies and many defects on $\mathrm{ZnO}$ nanoarrays, which will affect the transportation of photogenerated carriers and lead to the slow conduction process of photogenerated carriers ${ }^{34}$. When PWA is introduced into $\mathrm{ZnO}$, it can act as an electronic bridge because of its good electron absorption properties, thus prolonging the recombination time of photogenerated carriers in $\mathrm{ZnO}$, which has achieved the purpose of improving the photoelectronic properties of the composite.

\section{CONCLUSION}

In this paper, PProDOT-OH polymer was electrodeposited on hydrothermally grown $\mathrm{ZnO}$ nanoarrays by electrochemical deposition method to prevent the corrosion of $\mathrm{ZnO}$ by PWA, and then PWA was introduced into $\mathrm{ZnO} / \mathrm{PProDOT}-\mathrm{OH}$ by dripping method to prepare $\mathrm{ZnO} / \mathrm{PProDOT}-\mathrm{OH} / \mathrm{PWA}$ composite, and the UV detection properties of the composite were studied through assembling UV detectors. Under the irradiation of $365 \mathrm{~nm}$ UV light, the responsivity of the $\mathrm{ZnO} /$ PProDOT-OH/PWA composite based UV detector is $42 \mathrm{~A} \mathrm{~W}^{-1}$, which is 16.8 times higher than that of pure $\mathrm{ZnO}$ nanoarrays $\mathrm{UV}$ detector $\left(2.5 \mathrm{~A} \mathrm{~W}^{-1}\right)$, the external quantum efficiency (EQE\%) is increased from $850 \%$ to $14240 \%$, and the detection rate (D) is increased from the original $2.21 \times 10^{11}$ Jones to $2.8 \times 10^{12}$ Jones. Compared with pure ZnO-based UV detectors, the introduction of PWA can significantly improve the photoresponsivity of UV detectors. This study has potential application value in the fields of $\mathrm{ZnO}$-based $\mathrm{UV}$ detectors.

\section{LITERATURE CITED}

1. Xing, Y.J., Xi, Z.H., Xue, Z.Q., Zhang, X.D., Song, J.H, Wang, R.M., Xu, J., Song, Y., Zhang, S.L. \& Yu, D.P. (2003). Optical properties of the $\mathrm{ZnO}$ nanotubes synthesized via vapor phase growth. Appl. Phys. Lett., 83, 1689-1691. DOI: 10.1063/1.1605808.

2. Leung, Y.H., Djurisic, A.B., Choy, W., Chan, W.K. \& Cheah, K.W. (2004). ZnO nanostructures prepared by different methods. Mrs Proceedings. 818, M8.19.11. DOI: 10.1557/PROC-818-M8.19.1.

3. Gozeh, B.A., Karabulut, A., Yildiz, A. \& Yakuphanoglu, F. (2018). Solar light responsive $\mathrm{ZnO}$ nanoparticles adjusted using $\mathrm{Cd}$ and La Co-dopant photodetector. J. Alloys Compd., 732, 16-24. DOI: 10.1016/j.jallcom.2017.10.167.

4. Zheng, W., Ding, R., Yan, X. \& He, G. (2017). PEG induced tunable morphology and band gap of ZnO. Mater. Lett., 201, 85-88. DOI: 10.1016/j.matlet.2017.04.133.

5. Ocak, Y.S. (2012). Electrical characterization of DC sputtered $\mathrm{ZnO} / \mathrm{pSi}$ heterojunction. J. Alloys Compd., 513, 130-134. DOI: 10.1016/j. jallcom.2011.10.005.
6. Liu, K., Sakurai, M. \& Aono, M. (2010). ZnO-Based Ultraviolet Photodetectors. Sensors. 10, 8604-8634. DOI: 10.3390/s100908604.

7. Kind, H., Yan, H., Messer, B., Law, M. \& Yang, P. (2002). Nanowire ultraviolet photodetectors and optical switches. Adv. Mater, 14, 158-160. DOI:10.1002/1521-4095(20020116)14:2<158::AID-ADMA158>3.0.CO;2-W.

8. Suo, B., Wu, W., Qin, Y., Cui, N., Bayerl, D.J., Wang, X. (2011). High-performance integrated $\mathrm{ZnO}$ nanowire UV sensors on rigid and flexible substrates. Adv. Funct. Mater. 21, 4464-4469. DOI: 10.1002/ adfm.201101319.

9. Pope, M.T. \& Müller, A. (2010). Polyoxometalate chemistry: an old field with new dimensions in several disciplines. Angew. Chem. Int. Ed., 30, 34-48. DOI: 10.1002/anie.199100341.

10. Song, Y.F. \& Tsunashima, R. (2012). Recent advances on polyoxometalate-based molecular and composite materials. Chem. Soc. Rev., 41, 7384. DOI: 10.1039/c2cs35143a.

11. Pope, M.T. \& Müller, A. (2002). Polyoxometalate chemistry from yopology via self-assembly to applications || introduction to polyoxometalate chemistry : from topology via self-assembly to applications, 1-6. DOI: $10.1007 / 0-306-47625-8 \_1$.

12. Dolbecq, A., Dumas, E., Mayer, C.R. \& Mialane, P. (2010). ChemInform abstract: hybrid organic-inorganic polyoxometalate compounds: from structural diversity to applications. Chem. Rev., 110, 6009-6048. DOI: 10.1021/cr1000578.

13. Hill, C.L. \& Bouchard, D.A. (1985). Catalytic photochemical dehydrogenation of organic substrates by polyoxometalates. J. Am. Chem. Soc., 107, 5148-5157. DOI: 10.1021/ja00304a019.

14. Misono, M., Okuhara, T., Ichiki, T., Arai, T. \& Kanda, Y. (1987). Pseudoliquid behavior of heteropoly compound catalysts. Unusual pressure dependencies of the rate and selectivity for ethanol dehydration. Cheminform. 18, 5535-5536. DOI: 10.1002/chin.198748022.

15. Guo, Y., Hu, Ch., Jiang, S., Guo, C., Yang, Y., Wang, E., (2002). Heterogeneous photodegradation of aqueous hydroxy butanedioic acid by microporous polyoxometalates. Appl. Catal. B: Environ. DOI: 10.1016/S0926-3373(01)00260-0.

16. Gkika, E., Troupis, A., Hiskia, A. \& Papaconstantinou, E. (2006). Photocatalytic reduction of chromium and oxidation of organics by polyoxometalates. Appl. Catal. B Environ. 62, 28-34. DOI: 10.1016/j. apcatb.2005.06.012.

17. Troupis, A., Hiskia, A. \& Papaconstantinou, E. (2003). Photocatalytic reduction-recovery of silver using polyoxometalates. Appl. Catal. B Environ. 42, 305-315. DOI: 10.1016/S0926-3373(02)00264-3.

18. Maldotti, A., Amadelli, R., Varani, G., Tollari, S. \& Porta, F. (1994). Photocatalytic processes with polyoxotungstates: oxidation of cyclohexylamine. Inorg. Chem. 33, 2968-2973. DOI: 10.1021/ ic00091a041.

19. Papaconstantinou, E., Ioannidis, A., Hiskia, A., Argitis, P., Dimotikali, D. \& Korres, S. (1993). Photocatalytic processes by polyoxometalates. splitting of water. The role of dioxygen. Molec. Engin. 3, 231-239. DOI: 10.1007/BF00999635.

20. Hiskia, A. \& Papaconstantinou, E. (1992). Photocatalytic oxidation of organic compounds by polyoxometalates of molybdenum and tungsten. Catalyst regeneration by dioxygen. Inorg. Chem., 31, 163-167. DOI: $10.1021 / \mathrm{ic} 00028 \mathrm{a} 007$.

21. Sun, Z., Zhang, Y., Na, L., Lin, X. \& Wang, T. (2015). Enhanced photoconductivity of a polyoxometalate- $\mathrm{TiO}_{2}$ composite for gas sensing applications. J. Mater. Chem. C. 3, 6153-6157. DOI: 10.1039/c5tc00904a.

22. Benjamin D. Reeves, Unur, E., Ananthakrishnan, N. \& Reynoldset J.R. (2007). Defunctionalization of ester-substituted electro- 
chromic dioxythiophene polymers. Macromolecules. 40, 5344-5352. DOI: $10.1021 / \mathrm{ma} 070046 \mathrm{~d}$.

23. Yoon, Y.C., Park, K.S. \& Kim, S.D. (2015). Effects of low preheating temperature for $\mathrm{ZnO}$ seed layer deposited by sol-gel spin coating on the structural properties of hydrothermal $\mathrm{ZnO}$ nanorods. Thin Solid Films. 597, 125-130. DOI: 10.1016/j.tsf.2015.11.040.

24. Ghosh, R., Kundu, S., Majumder, R., Roy, S. Das, S., Banerjee, A., Guria, U., Banerjee, M., Bera, M.K., Subhedar, K.M. \& Chowdhury, M.P. (2019). One-pot synthesis of multifunctional $\mathrm{ZnO}$ nanomaterials: study of superhydrophobicity and UV photosensing property. Appl. Nanosci. DOI: 10.1007/s13204-019-00985-8.

25. Jamal, R., Li, Z., Wang, M., Qin, Z. \& Abdiryim, T. (2016). Synthesis of poly(3,4-propylenedioxythiophene)/MnO2 composites and their applications in the adsorptive removal of methylene blue. Progress Natur: Sci. 26, 32-40. DOI: 10.1016/j.pnsc.2016.01.001.

26. Yuan, X.Y., Luo, H.A., Yang, N.F. \& Liu, Y.J. (2006). Synthesis of long-chain pentaerythritol acetals catalyzed by phosphotungstic acid supported on active carbon under microwave irradiation. J. Hunan Univ. Nat. Sci. 33, 99-102. DOI: 10.1038/sj.cr.7310110.

27. Katiyar, A., Kumar, N. \& Srivastava, A. (2018). Optical properties of $\mathrm{ZnO}$ nanoparticles synthesized by co-precipitation method using LiOH. Mater. Today: Proceed. 5, 9144-9147. DOI: 10.1016/j. matpr.2017.10.034.

28. Moura, A.P., Lima, R.C., Moreira, M.L., Volanti, D.P., Espinosa, J.W.M., Orlandi, M.O., Pizani, P.S., Varela, J.A. \& Longo, E., (2010). $\mathrm{ZnO}$ architectures synthesized by a microwave-assisted hydrothermal method and their photoluminescence properties. Solid State Ionics. 181, 775-780. DOI: 10.1016/j.ssi.2010.03.013.

29. Chang, S.J., Duan, B.G., Hsiao, C.H., Young, S.J. \& Wu, S.L. (2013). Low-frequency noise characteristics of in-doped $\mathrm{ZnO}$ ultraviolet photodetectors. IEEE Phot. Technol. Letters. 25, 2043-2046. DOI: 10.1109/LPT.2013.2280719.

30. Mandalapu, L.J., Xiu, F.X., Yang, Z. \& Liu, J.L. (2007). Ultraviolet photoconductive detectors based on Ga-doped $\mathrm{ZnO}$ films grown by molecular-beam epitaxy. Solid-State Electron. 51, 1014-1017. DOI: 10.1016/j.sse.2007.05.009.

31. Mak, A., Mks, B., Kkn, A. \& Sbk, A. Defect and strain modulated highly efficient $\mathrm{ZnO}$ UV detector: Temperature and low-pressure dependent studies. Appl. Surf. Sci. 505. DOI: 10.1016/j.apsusc.2019.144365.

32. Hanna, B., Surendran, K.P. \& Narayanan Unni, K.N. (2018). Low temperature-processed $\mathrm{ZnO}$ thin films for $\mathrm{p}$-n junction-based visible-blind ultraviolet photodetectors. RSC Advanc. 8, 37365-37374. DOI: $10.1039 / \mathrm{C} 8 \mathrm{RA} 07312 \mathrm{~K}$.

33. Weng, WY., Chang S.J., Hsu, C.L., Hsueh, T.J., Chang, S.P. (2010). A lateral $\mathrm{ZnO}$ nanowire photodetector prepared on glass substrate. $J$. Electr. Soc. 157, K30-K33. DOI: 10.1149/1.3264650.

34. Fan, H.-B., Yang, S.-Y., Zhang, P.-F., Wei H.-Y., Liu X.-L., Jiao, Ch.-M., Zhu, Q.-S., Chen, Y.-H. \& Wang, Z.-G. (2008). Cross-disciplinary physics and related areas of science and technology: a simple route of morphology control and structural and optical properties of $\mathrm{ZnO}$ grown by metal-organic chemical vapour deposition. Chin. Phys. Letters. 25, 3063-3066. DOI: 10.1088/0256-307X/25/8/088. 